\title{
AN EXPERIMENTAL STUDY ON HEAT TRANSPORT CAPABILITY OF A TWO PHASE THERMOSYPHON CHARGED WITH DIFFERENT WORKING FLUIDS
}

\author{
${ }^{1}$ M. Kannan, ${ }^{1}$ R. Senthil, ${ }^{2}$ R. Baskaran and ${ }^{3}$ B. Deepanraj \\ ${ }^{1}$ Department of Mechanical Engineering, Adhiparasakthi Engineering College, Melmaruvathur, India \\ ${ }^{2}$ Department of Industrial Engineering, College of Engineering Guindy, Anna University Chennai, India \\ ${ }^{3}$ Department of Mechanical Engineering, National Institute of Technology Calicut, India
}

Received 2013-11-19; Revised 2014-01-08; Accepted 2014-02-01

\begin{abstract}
In the present investigation a two phase thermosyphon has been fabricated to investigate the effect of operating parameters on the heat transport capability. The system consists of evaporator section, adiabatic section and condenser section with thermocouples located on the wall of thermosyphon. Electric heater was fixed on the bottom of the evaporator section and water jacket for cooling the condenser was placed on the top of the condenser section of the thermosyphon. The experiments were conducted with three different thermosyphons with inner diameters of 6.7, 9.5 and $12 \mathrm{~mm}$. The variation of heat transport capability of the thermosyphon was studied for the input heat transfer rate ranging from 0 to $1200 \mathrm{~W}$ for various filling ratios and with operating temperature from 30 to $70^{\circ} \mathrm{C}$. Water, methanol, ethanol and acetone were used as working fluids. The maximum heat transport capability was found to be high for water compared to other fluids such as ethanol, methanol and acetone at the operating temperatures higher than $40^{\circ} \mathrm{C}$.
\end{abstract}

Keywords: Thermosyphon, Waste Heat Recovery, Heat Transport Capability, Inner Diameter, Filling Ratio

\section{INTRODUCTION}

A two phase closed thermosyphon is a heat pipe which needs no wicks to return condensate working fluid from condenser to evaporator in the heat transport process due to gravity, however, the evaporator must be positioned at the lower part than the condenser in the gravitation field (Park et al., 2002). Due to its simple structure, stable operating condition and wide operating temperature range, it is used in many industrial applications. The schematic view of a two phase closed thermosyphon is shown in Fig. 1 (Kannan and Natarajan, 2010).

In thermosyphon, the evaporator is partially filled with a working fluid, which is degassed and kept initially at a vacuum. The working fluid in the evaporator section absorbs the heat input in the form of sensible heat and mostly as latent heat vaporization. The vapor travels upward to the condenser section where it is converted in Corresponding Author: M. Kannan, Department of Mechanical Engineering, Adhiparasakthi Engineering College, Melmaruvathur, India to liquid, giving up its latent heat of condensation. The liquid then flows downward on the wall as a thin film under the effect of gravity to the evaporator section.

Many researchers (Baojin et al., 2009; Benkheira et al., 2007; EI-Genk and Huang, 1993; Huminic et al., 2011; Groll et al., 1981) have conducted experiments on the thermal performance of two phase closed thermosyphon using various working fluid and different pipe diameters. Amatachaya and Srimuang (2010) investigated the heat transfer characteristics of a Flat Two Phase Closed Thermosyphon (FTPCT) and Conventional Two Phase Closed Thermosyphon (CTPCT) using distilled water with different filling ratios, aspect ratios and heat input. It was observed that the FTPCT has higher average wall temperature in the evaporator section than that of CTPCT. The heat flux was increased with increase in aspect ratios and decreased slightly at maximum aspect ratio for both FTPCT and CTPCT. 


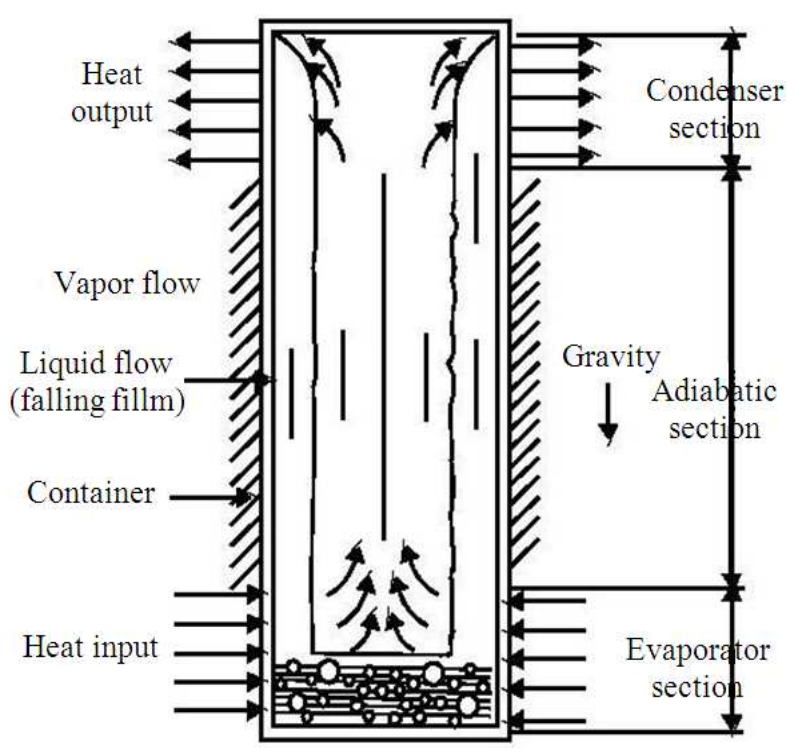

Fig. 1. Schematic view of two phase closed thermosyphon

Jouhara and Robinson (2010) investigated a small diameter and compact thermosyphon with four different working fluids: Water, FC-84, FC-77 and FC-3283 and reported that thermal performance of the water-charged thermosyphon outperformed the other three working fluids in both the effective thermal resistance as well as maximum heat transport capabilities. Payakaruk et al. (2000) described the effect of dimensionless parameters on heat transfer characteristics of an inclined thermosyphon and found that that the filling ratio has no effect on the ratio of heat transfer characteristics at any angle. Nakano et al. (1998) investigated heat transport characteristics of a cryogenic two-phase nitrogen thermosyphon and found that the maximum heat transfer rate is governed by the interaction between the vapor flow and the returning liquid film flow along the wall in the evaporator section, even near the critical point. Zuo and Gunnerson (1994) studied the steadystate performance of the gravity-assisted two-phase closed thermosyphon by varying the parameters like operating temperatures, geometry, working fluid inventory and condenser thermal capacity and reported that the changes of mass flow rate of condenser cooling water significantly affect the heat transfer capacity, especially while the mass flow rate is low. Li et al. (1991) investigated the steady state heat transfer characteristics for vertical two-phase closed thermosyphons at low temperature differences with R11, R22 and water as working fluid and found the minimum temperature difference required to initiate and sustain boiling in the low temperature thermosyphons. Imura et al. (1983) has conducted experimental study on critical heat flux in closed two phase thermosyphon for various working fluids like water, ethanol and freon113 for two different diameters (19.4 and $13.1 \mathrm{~mm})$. It was observed that increase in operating temperature increases the heat flux. Groll et al. (1981) has conducted experiment on reflux heat pipes with and without wick as a components in heat exchangers for different inclination and diameters using water as a working fluid. It was observed that maximum heat transport capability increases with increase in tilting angle and operating temperature. This study presents the heat transfer capability of the two phase closed thermosyphon charged with water as well as other three working fluids such as ethanol, methanol and acetone with three different diameters at various filling ratios and operating temperatures.

\section{MATERIALS AND METHODS}

\subsection{Experimental Setup}

The experimental setup used for the present research work is shown in Fig. 2. The test rig consists of a heater, a liquid reservoir for charging, a thermosyphon (wickless heat pipe), a cooling section and also measuring instruments. The upper part of the thermosyphon is equipped with a seal valve for connection to a mechanical vacuum pump and other side the working fluid is charged through burette valve for sending accurate amount of working fluid to the thermosyphon. A mechanical vacuum pump capable of up to $0.5 \mathrm{~Pa}$ used for partial elimination of the NonCondensable Gases (NCG) from the thermosyphon. Complete extraction of NCG is achieved by purging.

In the experiment three different diameters of $6.7,9.5$ and $12 \mathrm{~mm}$ thermosyphon are used. The detail of thermosyphon with an electric heater for evaporator section and a water jacket for condenser section is shown in Fig. 3 with inner diameter of $9.5 \mathrm{~mm}$. The thermosyphon consist of $1000 \mathrm{~mm}$ long tube having an inside diameter of $6.7 \mathrm{~mm}$ and outside diameter of $8 \mathrm{~mm}$. The tube is sealed at one end and provided with a vacuum valve at the other end. The evaporator section has the length of $300 \mathrm{~mm}$ and adiabatic section has the length of $200 \mathrm{~mm}$. The condenser section of the pipe consists of a $500 \mathrm{~mm}$ long (30 mm OD) concentric tube acting as a cooling water jacket surrounding the pipe. Similarly the thermosyphon of $1000 \mathrm{~mm}$ long tube having an inside diameter of $9.5 \mathrm{~mm}$ and outside diameter of $12.5 \mathrm{~mm}$ with condenser section of the pipe $500 \mathrm{~mm}$ long (40 $\mathrm{mm} \mathrm{OD)}$ and inner diameter $12 \mathrm{~mm}$ and outer diameter $16 \mathrm{~mm}$ with same condenser section were used for the tests. 


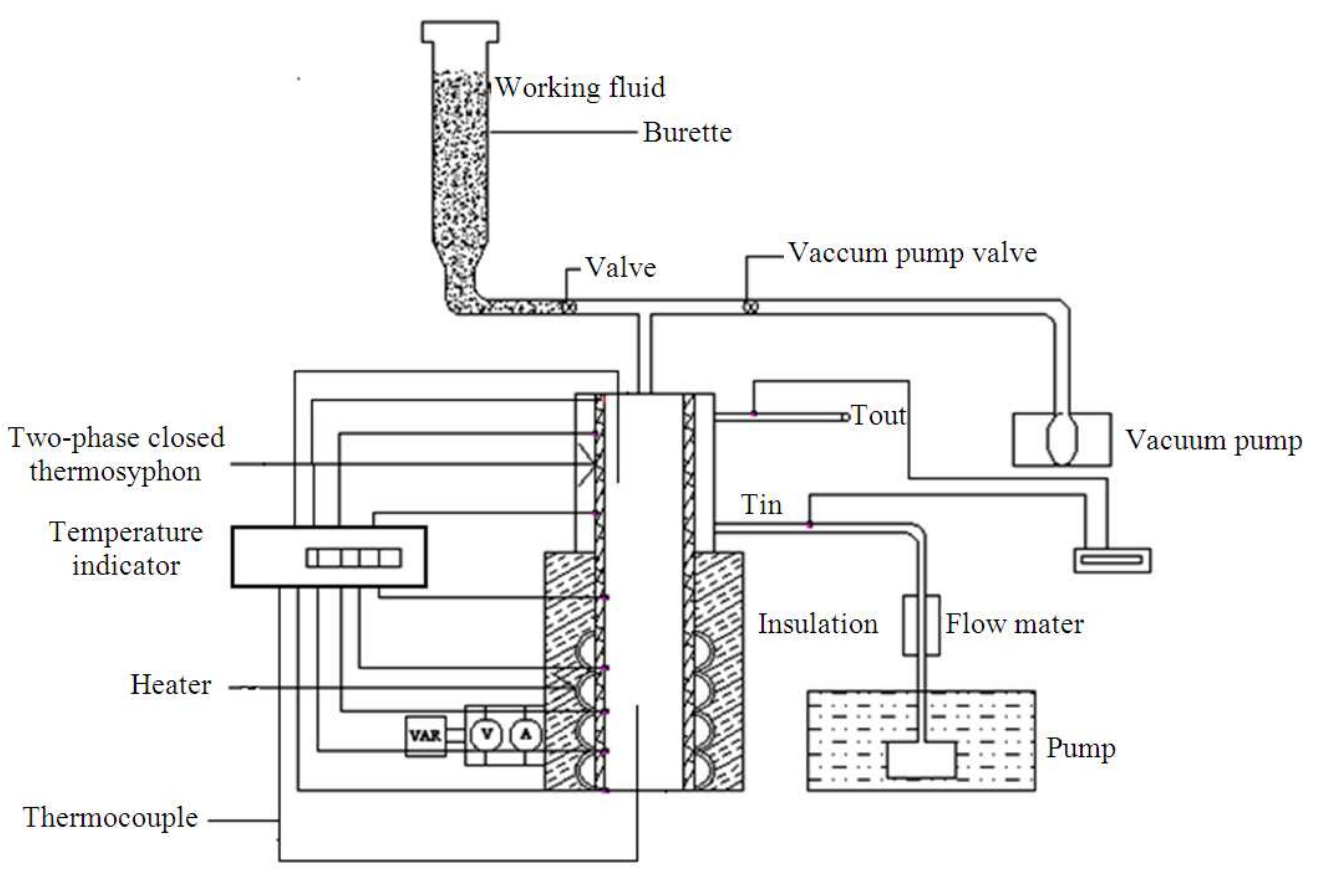

Fig. 2. Schematic of the test rig

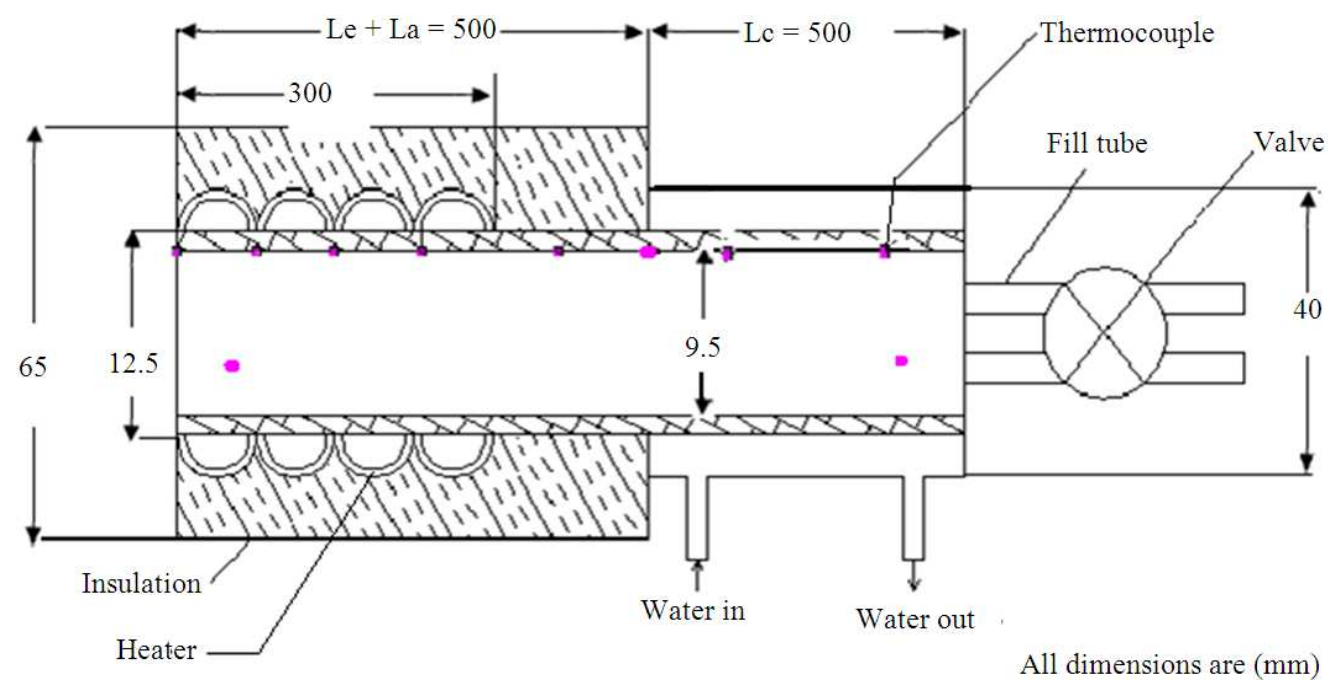

Fig. 3. Details of thermosyphon with ID $9.5 \mathrm{~mm}$

An electrical resistance of a nominal power range of 0 to $1200 \mathrm{~W}$ is wrapped around the evaporator section, which is used to heat the evaporator. To prevent the heat loss to the atmosphere, the electrical elements are insulated by glass wool having a thickness of $65 \mathrm{~mm}$. The heat is removed from the condenser section by the water jacket as described in the introduction.
The power supplied to the evaporator section is determined by monitoring the applied voltage and current with accuracy of $\pm 2 \%$. The accuracy of flow measurement is estimated to be around $\pm 2 \%$. A variable voltage controlled the rate of heat transfer the evaporator. Temperature distribution along the thermosyphon is measured using $\mathrm{Ni}-\mathrm{Cr}$ thermocouple. 
The upper surface of thermocouple is fully insulated and the vacuum pressure also measured by using the vacuum pressure gauge.

In order to find out the effects of maximum heat transfer capability on the thermal performance of the thermosyphon a series of more than 1000 tests are carried out for the following conditions:

Input heat transfer rate range: $0 \mathrm{~W}$ to $1200 \mathrm{~W}$

Filling ratio $(\%)$ :

$30,40,50,60,70,80$ and 90

Operating Temperature $\left({ }^{\circ} \mathrm{C}\right): \quad 30,35,40,45,50,55$, 60,65 and 70

Working fluids: Water, ethanol, methanol and acetone

Inner Diameter thermosyphon: 6.7, 9.5, $12 \mathrm{~mm}$

\subsection{Experimental Procedure}

The evaporator section of thermosyphon of selected type $(6.7,9.5$ and $12 \mathrm{~mm})$ is fitted into the $300 \mathrm{~mm}$ long heater block in the test rig and the condenser section is covered by a $500 \mathrm{~mm}$ long water jacket. The whole system is then completely insulated. Then the thermosyphon is filled with required working fluid with the filling ratio varying from 30 to $90 \%$ of evaporator volume.

Test procedure began by charging a required working fluid. In the first series of experiments, the thermosyphon is filled with distilled water. The thermal performance of the thermosyphon for different working fluids, filling ratio and operating temperature is investigated. Heat is supplied by an electrical heater wrapped around the thermosyphon, along the $300 \mathrm{~mm}$ long evaporator section. Heat is removed by a constant temperature cooling flowing through respective channels in a $500 \mathrm{~mm}$ long condenser back. All thermosyphon are subjected to cyclic variations of the heat input (gradually increase from $0 \mathrm{~W}$ to nominal power within $20 \mathrm{~min}$ holding at this power for $9 \mathrm{~min}$, gradually decrease to $0 \mathrm{~W}$ within $25 \mathrm{~min}$, holding at $0 \mathrm{~W}$ for $9 \mathrm{~min}$ ) The maximum power, at which the wall temperature of thermosyphon is high, is recorded. At that condition the maximum heat transport rate is measured. This procedure is repeated for all working fluids. The same test procedure is repeated for three different inner diameters like $6.7,9.5$ and $12 \mathrm{~mm}$ of thermosyphon. The heat losses in the evaporator section is very low for all the test conditions and the percentage range of heat loss to total power supplied is very minimum. So, we are neglecting the heat loss from evaporators.

\subsection{Performance of Closed Two Phase Thermosyphon}

By investigating the closed two phase thermosyphon, the following limitations are observed.

Entrainment is encountered when the axial heat flow exceeded certain limit. It depends upon the diameter and working fluids. Experiment cannot be continued beyond this $\mathrm{Q}_{\max }$ it will lead to dry out indicated by the drastic increase in temperature of a evaporator section.

The boiling limit or burn out limitation appears under high radial heat fluxes in the evaporator section. Within the $\mathrm{Q}_{\max }$ used in the experiment no dry out and boiling limit were encountered. To verify the measured results, the following correlation between the maximum heat transport capability and the various influence parameters is used:

$$
\mathrm{Q}_{\max }=\left\{\mathrm{f}_{1} \mathrm{f}_{2} \mathrm{f}_{3} \mathrm{~L}\left(\rho_{\mathrm{v}}\right)^{1 / 2}\left[\gamma \mathrm{g}\left(\rho_{\mathrm{l}}-\rho_{\mathrm{v}}\right)^{1 / 4}\right\} \mathrm{A}_{\mathrm{E}}^{\prime}\right.
$$

\section{RESULTS AND DISCUSSION}

The two phase closed thermosyphon with internal diameters of $6.7,9.5$ and $12 \mathrm{~mm}$ are fabricated to investigate the influence of filling ratio, operating temperature, working fluids on the heat transport capability of thermosyphon (wickless heat pipe). Water, methanol, ethanol and acetone are used as working fluids. The results obtained are discussed.

\subsection{Water as Working Fluid}

The variations of heat transport capability with filling ratio for water in $6.7 \mathrm{~mm}$ inner diameter thermosyphon is shown in Fig. 4-6. As the operating temperature increases the heat transport capability also increases. The heat transport capability increases from $174 \mathrm{~W}$ at $30^{\circ} \mathrm{C}$ to $360 \mathrm{~W}$ at $70^{\circ} \mathrm{C}$, as shown in Fig. 4. As filling ratio increases, the heat transport capability also increases and reached maximum at around $60 \%$ filling ratio and then decreases.

The variation of heat transport capability with filling ratio for the thermosyphon of $9.5 \mathrm{~mm}$ inner diameter is found to exhibit similar pattern as that of $6.7 \mathrm{~mm}$ inner diameter thermosyphon, but it is found to increase from 354 to $687 \mathrm{~W}$ when the operating temperature increases from 30 to $70^{\circ} \mathrm{C}$, as shown in Fig. 5 . 


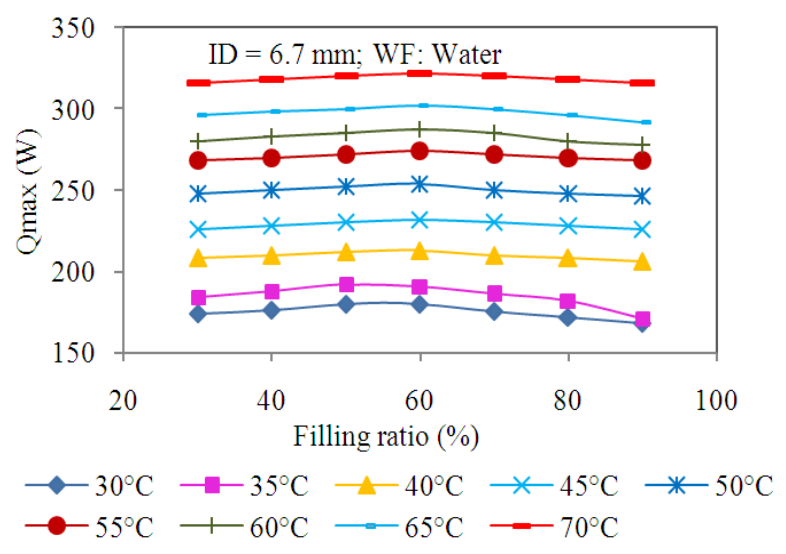

Fig. 4. Heat transport capability for water with inner diameter $6.7 \mathrm{~mm}$

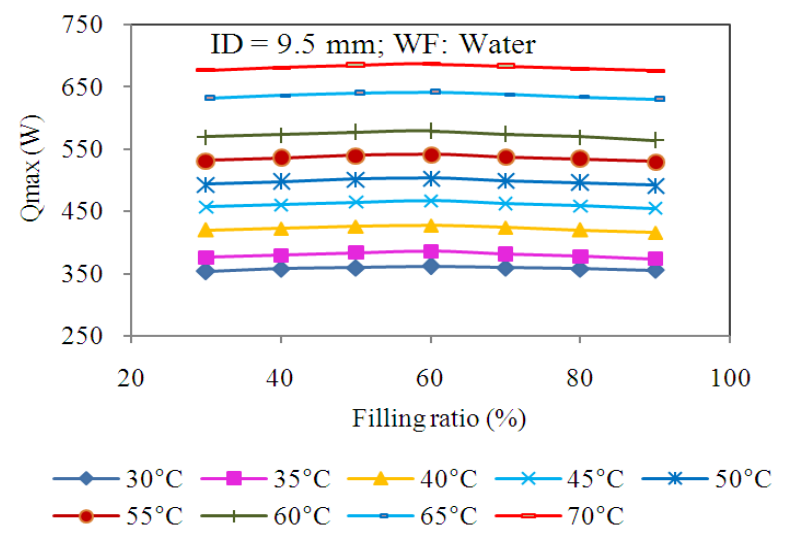

Fig. 5. Heat transport capability for water with inner diameter $9.5 \mathrm{~mm}$

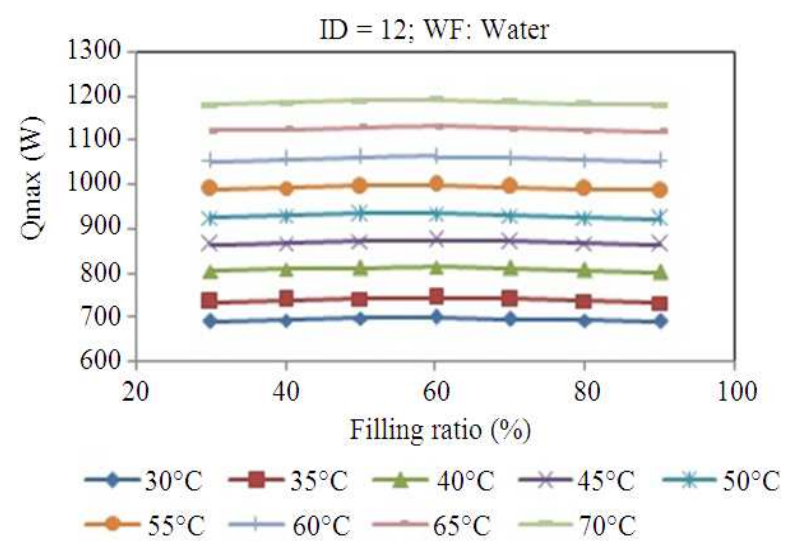

Fig. 6. Heat transport capability for water with inner diameter $12 \mathrm{~mm}$
The heat transport capability is found to increase from 688 to $1189 \mathrm{~W}$ for inner diameter $12 \mathrm{~mm}$ when the operating temperature is increased from 30 to $70^{\circ} \mathrm{C}$, as shown in Fig. 6. Groll experiments deals with only water as a working fluid but for different inclination, five different diameters, surface roughness, smooth pipe and for with and without wick. Our experiments deals with different working fluids (water, ethanol, methanol, acetone) for smooth vertical wickless heat pipe of thermosyphon type. The trends with increase in temperature increases heat transfer capability fairly match with this experiment.

\subsection{Methanol as Working Fluid}

The variation of heat transport capability with various filling ratios for methanol as a working fluid for different operating temperature shown in Fig. 7-9. The heat transport capability increases from 130 to $228 \mathrm{~W}$ at the range of operating temperature from 30 to $70^{\circ} \mathrm{C}$ for the thermosyphon of $6.7 \mathrm{~mm}$ inner diameter as shown in Fig. 7. It is found that the heat transport capability increase from 296 to $517 \mathrm{~W}$ for inner diameter $9.5 \mathrm{~mm}$ and when the operating temperature increases from 30 to $70^{\circ} \mathrm{C}$, as shown in Fig. 8. Figure 9 shows the heat transport capability ranges from 532 to $872 \mathrm{~W}$ for inner diameter $12 \mathrm{~mm}$ when the operating temperature ranges from 30 to $70^{\circ} \mathrm{C}$.

\subsection{Ethanol as Working Fluid}

The variation of heat transport capability with various filling ratios for ethanol as a working fluid for different operating temperature are shown in Fig. 10-12. As the operating temperature increases the heat transport capability increases from $90 \mathrm{~W}$ at $30^{\circ} \mathrm{C}$ to $167 \mathrm{~W}$ at $70^{\circ} \mathrm{C}$, for the thermosyphon of $6.7 \mathrm{~mm}$ inner diameter as shown in Fig. 10. It is observed that the heat transport capability also increases from 30 to $60 \%$ filling ratio and then decreases. For the thermosyphon of $9.5 \mathrm{~mm}$ inner diameter the heat transport capability found to exhibit similar pattern as that of $6.7 \mathrm{~mm}$ inner diameter thermosyphon, but it is found to increase from 206 to $378 \mathrm{~W}$ when the operating temperature increases from 30 to $70^{\circ} \mathrm{C}$, as shown in Fig. 11. It is observed that for inner diameter $12 \mathrm{~mm}$ of thermosyphon the heat transport capability is found to increase from 358 to $636 \mathrm{~W}$, when the operating temperature ranges from 30 to $70^{\circ} \mathrm{C}$ as shown in Fig. 12. Similar trend was observed by Imura et al. (1983) who has studied the critical heat flux for various working fluids, like water, ethanol and freon 113 and also the influence of thermosyphon with different inside diameter. 
M. Kannan et al. / American Journal of Applied Sciences 11 (4): 584-591, 2014

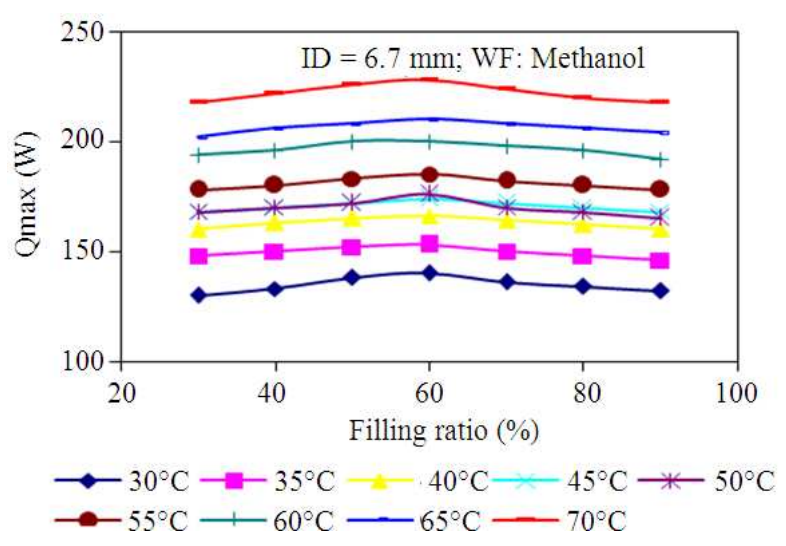

Fig. 7. Heat transport capability for methanol with inner diameter $6.7 \mathrm{~mm}$

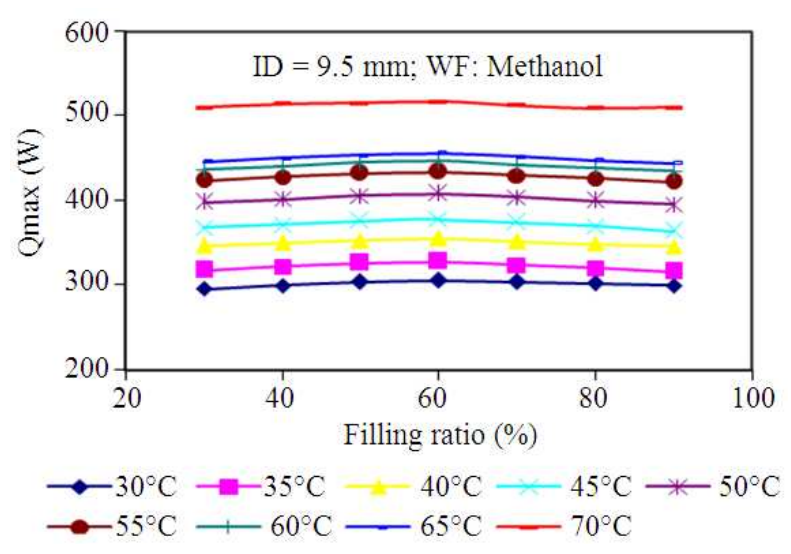

Fig. 8. Heat transport capability for methanol with inner diameter $9.5 \mathrm{~mm}$

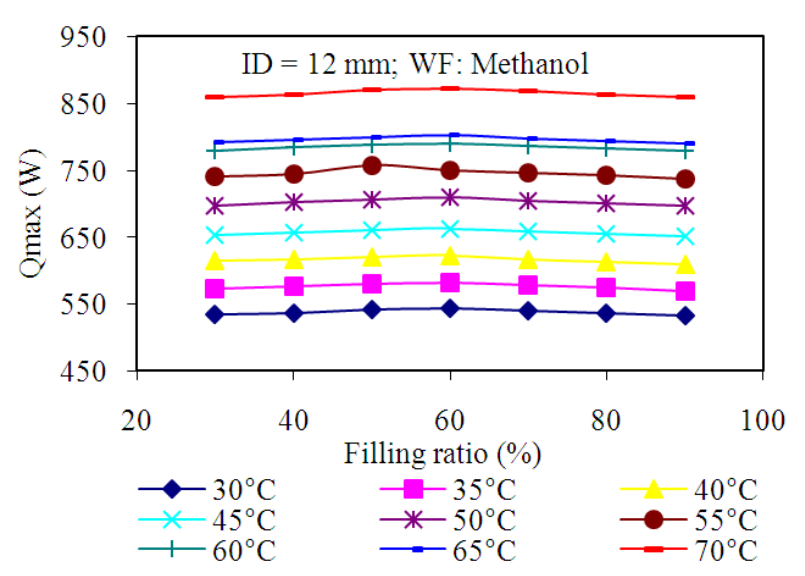

Fig. 9. Heat transport capability for methanol with inner diameter $12 \mathrm{~mm}$

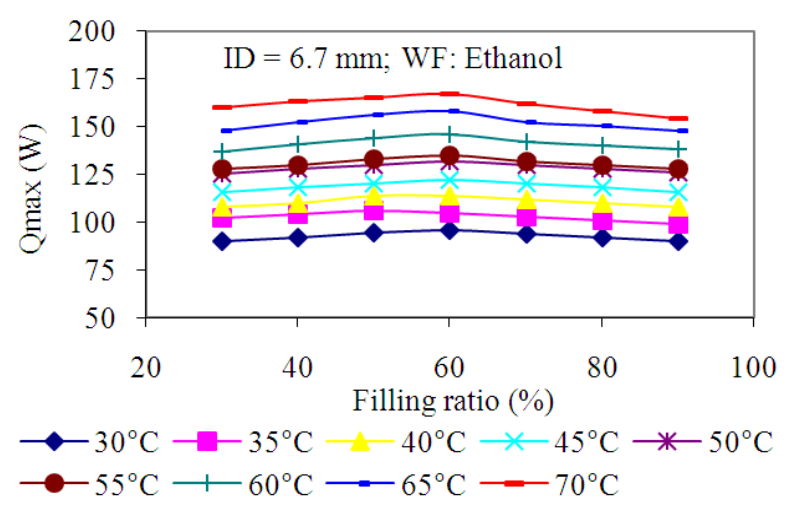

Fig. 10. Heat transport capability for ethanol with inner diameter $6.7 \mathrm{~mm}$

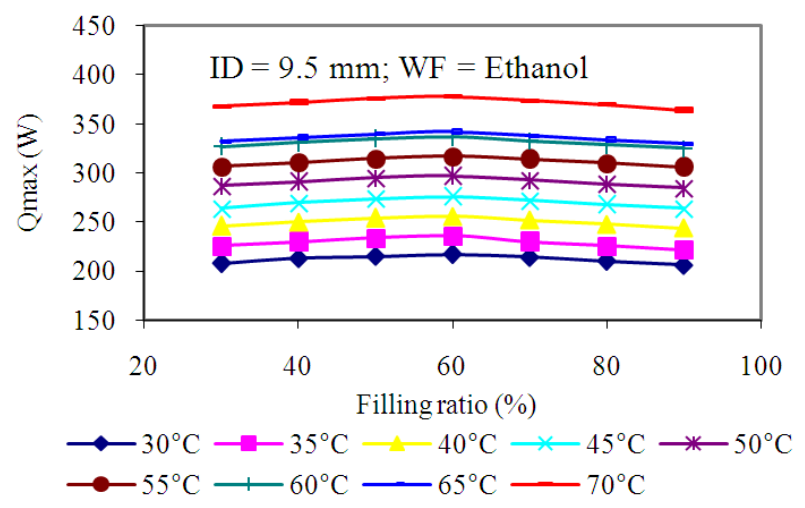

Fig. 11. Heat transport capability for ethanol with inner diameter $9.5 \mathrm{~mm}$

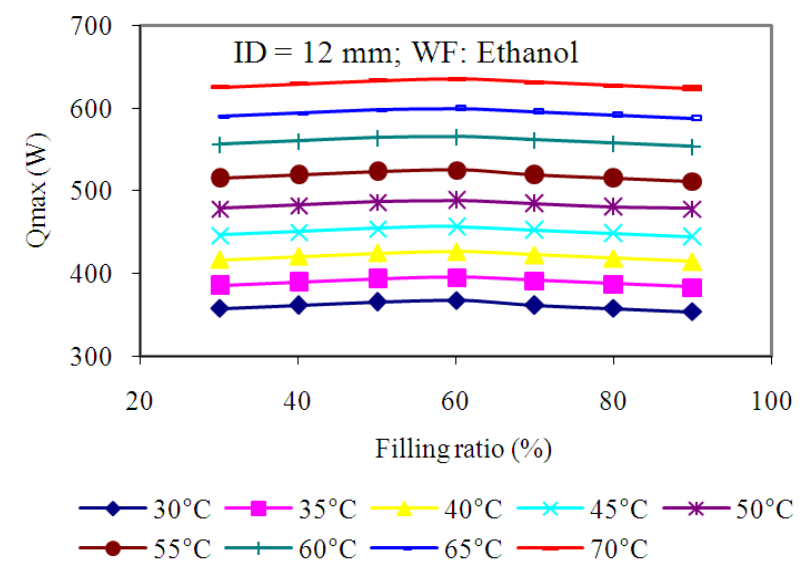

Fig. 12. Heat transport capability for ethanol with inner diameter $12 \mathrm{~mm}$ 


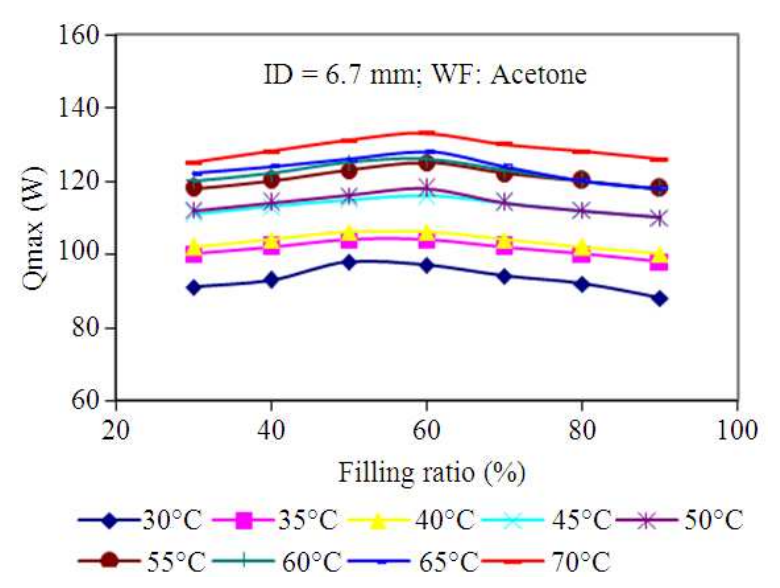

Fig. 13. Heat transport capability for acetone with inner diameter $6.7 \mathrm{~mm}$

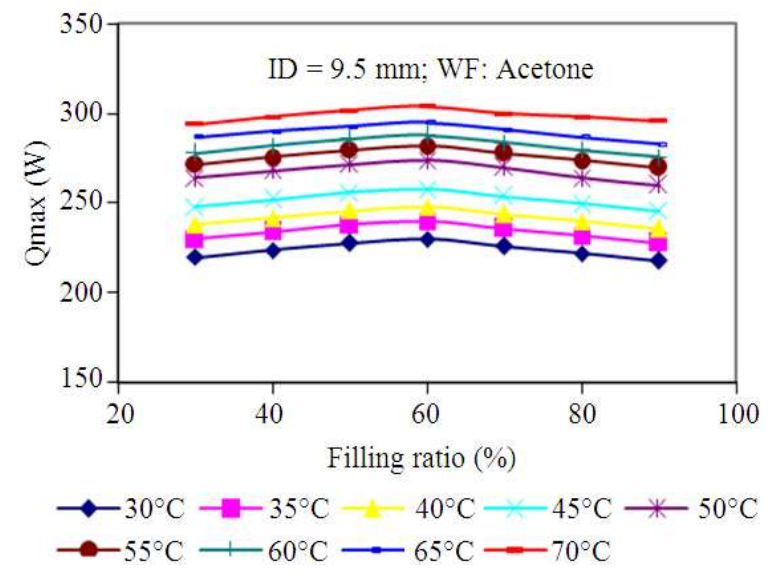

Fig. 14. Heat transport capability for acetone with inner diameter $9.5 \mathrm{~mm}$

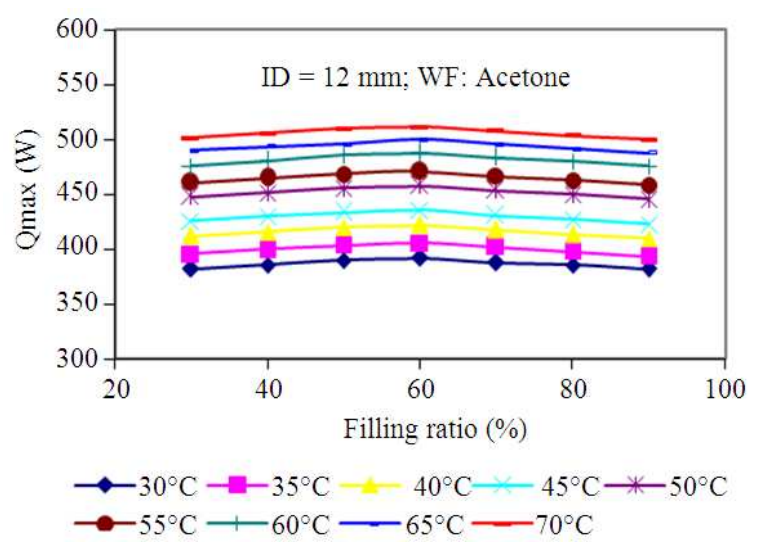

Fig. 15. Heat transport capability for acetone with inner diameter $12 \mathrm{~mm}$

\subsection{Acetone as Working Fluid}

The variation of heat transport capability with various filling ratios for acetone as a working fluid for different operating temperature shown in Fig. 13-15. As the operating temperature increases from 30 to $70^{\circ} \mathrm{C}$ the heat transport capability also increases from 91 to $133 \mathrm{~W}$, as shown in Fig. 13 for the thermosyphon with inner diameter of $6.7 \mathrm{~mm}$. It is found that for the thermosyphon of $9.5 \mathrm{~mm}$ inner diameter the heat transport capability increase from 220 to $304 \mathrm{~W}$ when the operating temperature increases from 30 to $70^{\circ} \mathrm{C}$, as shown in Fig. 14. The heat transport capability is found to increase from 382 to $512 \mathrm{~W}$ for inner diameter $12 \mathrm{~mm}$ of thermosyphon when the operating temperature is increased from 30 to $70^{\circ} \mathrm{C}$ as shown in Fig. 15 .

\section{CONCLUSION}

Experiments are conducted more than 1000 times with three different thermosyphons of inner diameters $6.7,9.5$ and $12 \mathrm{~mm}$. The variation of heat transport capability of the thermosyphons are studied for the input heat transfer rate ranging from 0 to $1200 \mathrm{~W}$ for various filling ratios and with operating temperature from 30 to $70^{\circ} \mathrm{C}$. Water, methanol and ethanol are used as working fluids. On the basis of results the following conclusions:

- The maximum heat transport capability shows a increasing trend with increasing operating temperature. The effect of filling ratio on heat transport capability is only marginal for all fluids

- As the operating temperature increases from 30 to $70^{\circ} \mathrm{C}$, maximum heat transport capability increases for water with $6.7 \mathrm{~mm}$ inner diameter thermosyphon from 174 to $360 \mathrm{~W}$ for $9.5 \mathrm{~mm}$ inner diameter thermosyphon it increases from 354 to $687 \mathrm{~W}$ and for $12 \mathrm{~mm}$ inner diameter thermosyphon it varies from $688 \mathrm{~W}$ to $1189 \mathrm{~W}$. Similar trend has been observed by Groll et al. (1981)

- For methanol, maximum heat transport capability increases from 130 to $228 \mathrm{~W}$ for $6.7 \mathrm{~mm}$ inner diameter thermosyphon for $9.5 \mathrm{~mm}$ inner diameter thermosyphon, it increases from 296 to $517 \mathrm{~W}$ and for $12 \mathrm{~mm}$ inner diameter thermosyphon it varies from 532 to $872 \mathrm{~W}$ when the operating temperature increases from 30 to $70^{\circ} \mathrm{C}$

- For $6.7 \mathrm{~mm}$ inner diameter thermosyphon maximum heat transport capability increases from 90 to 167 $\mathrm{W}$, for $9.5 \mathrm{~mm}$ inner diameter thermosyphon, it increases from 206 to $378 \mathrm{~W}$ and for $12 \mathrm{~mm}$ inner diameter thermosyphon, it varies from 358 to $636 \mathrm{~W}$ 
when the operating temperature increases from 30 to $70^{\circ} \mathrm{C}$ for ethanol as working fluid. Similar trend has been observed by Imura et al. (1983)

- While operating with acetone, the maximum heat transport capability increases from 91 to $133 \mathrm{~W}$ for $6.7 \mathrm{~mm}$ inner diameter thermosyphon. For $9.5 \mathrm{~mm}$ inner diameter thermosyphon, it increases from 220 to $304 \mathrm{~W}$ and for $12 \mathrm{~mm}$ inner diameter thermosyphon; it varies from 382 to $512 \mathrm{~W}$ when the operating temperature increases from 30 to $70^{\circ} \mathrm{C}$

- For the operating temperature range of 30 to $70^{\circ} \mathrm{C}$, water attains high maximum heat transport capability compared with other fluids such as ethanol, methanol and acetone.

- Acetone has low maximum heat transport capability for the operating temperature range between 30 and $70^{\circ} \mathrm{C}$

\section{REFERENCES}

Amatachaya, P., W. Srimuang, 2010. Comparative heat transfer characteristics of a Flat Two-Phase Closed Thermosyphon (FTPCT) and a Conventional TwoPhase Closed Thermosyphon (CTPCT). Int. Commun. Heat Mass Transfer, 37: 293-298. DOI: 10.1016/j.icheatmasstransfer.2009.11.004

Baojin, Q., Z. Li, X. Hong and S. Yan, 2009. Heat transfer characteristics of titanium/water two-phase closed thermosyphon. Energy Conver. Manage., 50: 2174-2179. DOI: 10.1016/j.enconman.2009.04.030

Benkheira, L., B. Baudouy and M. Souhar, 2007. Heat transfer characteristics of two-phase He I (4.2 K) thermosiphon flow. Int. J. Heat Mass Transfer, 50: 3534-3544.

DOI:

10.1016/j.ijheatmasstransfer.2006.12.032

EI-Genk, MS. and L. Huang, 1993. An experimental investigation of the transient response of a water heat pipe. Int. J. Heat Mass Transfer, 36: 3823-3830. DOI: 10.1016/0017-9310(93)90062-B

Groll, M., H.N. Chi and H. Krahling, 1981. Reflux heat pipes as components in heat exchangers for efficient heat recovery. Heat Recovery Syst., 1: 55-63. DOI: 10.1016/0198-7593(81)90005-9

Huminic, G., A. Huminic, I. Morjan and F. Dumitrache, 2011. Experimental study of the thermal performance of thermosyphon heat pipe using iron oxide nanoparticles. Int. J. Heat Mass Transfer, 54: 656-661.

DOI: 10.1016/j.ijheatmasstransfer.2010.09.005
Imura, H., K. Sasagucchi, H. Kozai and S. Numata, 1983. Critical heat flux in a closed two-phase thermosyphon. Int. J. Heat Mass Transfer, 26: 11811188. DOI: 10.1016/S0017-9310(83)80172-0

Jouhara, H. and A.J. Robinson, 2010. Experimental investigation of small diameter two-phase closed thermosyphons charged with water, FC-84, FC-77 and FC-3283. Applied Thermal Eng., 30: 201-211. DOI: 10.1016/j.applthermaleng.2009.08.007

Kannan, M. and E. Natarajan, 2010. Thermal performance of a two phase closed thermosyphon for waste heat recovery system. J. Applied Sci., 10: 413-418. DOI: 10.3923/jas.2010.413.418

Li, H., A. Akbarzadeh and P. Johnson, 1991. The thermal characteristics of a closed two-phase thermosyphon at low temperature difference. Heat Recovery Syst. CHP, 11: 533-540. DOI: 10.1016/0890-4332(91)90055-9

Nakano, A., M. Shiraishi, M. Nishio and M. Murakami, 1998. An experimental study of heat transfer characteristics of a two-phase nitrogen thermosyphon over a large dynamic range operation. Cryogenics, 38: 1259-1266. DOI: 10.1016/S00112275(98)00109-X

Park, Y.J., H.K. Kang and C.J. Kim, 2002. Heat transfer characteristics of a two-phase closed thermosyphon to the fill charge ratio. Int. J. Heat Mass Transfer, 45: 4655-4661. DOI: 10.1016/S00179310(02)00169-2

Payakaruk, T., P. Terdtoon and S. Ritthidech, 2000. Correlations to predict heat transfer characteristics of an inclined closed two-phase thermosyphon at normal operating conditions. Applied Thermal Eng., 20: 781-790. DOI: 10.1016/S1359-4311(99)00047-2

Zuo, Z.J. and F.S. Gunnerson, 1994. Numerical modeling of the steady-state two-phase closed thermosyphon. Int. J. Heat Mass Transfer, 37: 27152722. DOI: 10.1016/0017-9310(94)90388-3 